\title{
QS能
}

Juan Francisco Martínez García*

Blanca Revenga Martínez de Pazos**

\section{EL COMERCIO EN LAS RELACIONES TRANSATLÁNTICAS}

Las relaciones comerciales transatlánticas sobreviven a todas las vicisitudes, cambios y sobresaltos de los últimos dos años $\mathrm{y}$, de momento, siguen aumentando en volumen e intensidad. Durante los últimos años hemos asistido al fracaso de un ambicioso intento de impulsar una mayor integración, de la mano de un acuerdo bilateral, la Asociación Transatlántica para el Comercio y la Inversión (ATCI), más conocido por su acrónimo en lengua inglesa, TTIP (Transatlantic Trade and Investment Partnership), cuya negociación se interrumpió con el cambio de inquilino en la Casa Blanca. Desde ese momento, el cambio en la política comercial norteamericana, que se ha tornado mucho más unilateral, ha abierto una nueva etapa en las relaciones comerciales transatlánticas, en las que de momento destacan algunos nuevos irritantes comerciales originados por las decisiones unilaterales. Se mantiene la incertidumbre sobre si las actuales tensiones en el diálogo bilateral se mantendrán o se podrán reconducir hacia una dinámica positiva que quizá dé lugar a nuevas negociaciones a una escala menor.

Palabras clave: economía transatlántica, comercio, relaciones comerciales transatlánticas, Asociación Transatlántica para el Comercio y la Inversión, política comercial norteamericana.

Clasificación JEL: F13, F14, F15, N72.

\section{Introducción}

Es un tópico comenzar este tipo de artículos destacando la importancia de las relaciones comerciales transatlánticas. No por ser un tópico deja de ser verdad. La Unión Europea y Estados Unidos tienen la relación comercial bilateral de mayor peso en el mundo. Contemplando

\footnotetext{
* Consejero Económico y Comercial de España en la Representación Permanente de España ante la Unión Europea.

** Jefe de Área de Norteamérica. Subdirección General de Iberoamérica y América del Norte.

Versión de marzo de 2019.

DOI: https://doi.org/10.32796/bice.2019.3110.6804
}

exportaciones e importaciones de mercancías, con datos de Eurostat, el comercio de mercancías alcanzó un máximo en 2018 con 674 millardos de euros. Somos mutuamente nuestros principales socios comerciales, ya que, con datos de 2018 , el $17 \%$ del comercio total de la UE se produce con EE UU y el $19 \%$ del comercio total de EE UU tiene lugar con la UE. La inversión mutua alcanza también niveles excepcionales: la inversión total de EE UU en la UE es tres veces mayor que en toda Asia y la inversión de la UE en EE UU es casi ocho veces la cantidad de inversión de la UE en India y China juntas. 
La razón para avanzar aún más en la profundización de las relaciones comerciales no es otra que el peso de ambas áreas en la economía mundial, más del $45 \%$ del PIB mundial, lo que permite intuir un potencial de comercio $e$ inversión aún mayor.

El principal intento para impulsar esa mayor integración en los últimos tiempos se produjo, como es natural, en el proceso de recuperación económica tras la recesión mundial del año 2008, en un contexto favorable para tratar de explotar todas las vías posibles para impulsar el crecimiento económico sobre la base de la apertura de los mercados, en un momento en que se trataba también, desde el G20 y otros foros y organismos internacionales, de aconsejar resistir la tentación de aplicar medidas proteccionistas. Ese intento se materializó en una negociación comercial bilateral que se inició a mediados de 2013 y se prolongó durante más de tres años, hasta su interrupción, en diciembre de 2016.

En las próximas líneas nos referiremos someramente al antes, el durante y el después de ese proceso de negociación comercial bilateral.

\section{Génesis del TTIP}

La iniciativa para la negociación de un nuevo acuerdo comercial empezó a tomar cuerpo en un marco institucional creado en 2007 para impulsar la profundización de la relación transatlántica:el Consejo EconómicoTransatlántico.

El Consejo Económico Transatlántico proporcionaba una buena plataforma para brindar orientación política a este trabajo, ya que el TEC (por sus siglas en inglés) incorporaba tres grupos asesores: el Diálogo de los Legisladores Transatlánticos, el Diálogo Transatlántico de los Consumidores y el Diálogo Empresarial
Transatlántico, y, además, este informaba sobre sus objetivos y trabajos a la sociedad civil inmediatamente después de sus reuniones anuales.

Como resultado de la Cumbre UE-EE UU de noviembre de 2011, se solicitó al TEC que creara un Grupo de Trabajo de Alto Nivel sobre Empleo y Crecimiento (EU-US High Level Working Group on Jobs and Growth), dirigido por el comisario de Comercio de la UE y el Representante de Comercio de EE UU (USTR), que identificara y valorase las distintas opciones que mejorasen las relaciones bilaterales comerciales y de inversión de modo que, según se recogía en la declaración, se fomentase la creación de empleo, el crecimiento económico y la competitividad internacional a ambos lados del Atlántico.

A pesar de que tanto la UE como EE UU quisieron dejar claro que se pretendía explorar todas las opciones posibles, desde un TECplus hasta un potencial ALC entre las dos regiones del Atlántico, el trabajo del grupo se centró en explorar las posibilidades de un ALC de amplio espectro, lo que se ha dado en denominar un acuerdo comercial de nueva generación, que incorpora en su texto un ámbito mucho mayor que un simple desarme arancelario.

El grupo de trabajo presentó un informe provisional sobre su labor en junio de 2012, recomendando un acuerdo de libre comercio de amplio espectro, y desde ese momento se centró en definir la estructura y contenido del futuro acuerdo.

Tras una reunión del Consejo Europeo (7 y 8 de febrero de 2013) en la que los jefes de Estado de la UE manifestaron su compromiso con el comercio exterior, como clave para generar crecimiento económico y fomentar la creación de empleo, y afirmaron que los acuerdos de libre comercio son una herramienta muy útil para progresar en la liberalización comercial y $\triangleright$ 
hacer avanzar lo multilateral, el informe final se presentó el 13 de febrero de 2013.

Como se preveía, el grupo de trabajo llegó a la conclusión de que un acuerdo integral que abordase una amplia gama de asuntos bilaterales de comercio e inversión proporcionaría los mayores beneficios de entre todas las opciones consideradas y presentaba una estructura del mismo con tres pilares.

\section{Primer pilar: acceso a mercados}

- Comercio de bienes (aranceles, reglas de origen y salvaguardias).

- Comercio de servicios.

- Inversiones.

- Compras públicas.

Segundo pilar: barreras no arancelarias $y$ aspectos regulatorios

- Medidas sanitarias y fitosanitarias (SPS).

- Barreras técnicas al comercio (TBT).

- Coherencia regulatoria: regulación horizontal.

- Regulación sectorial: nueve sectores (cosmética, automóvil, farmaceútico, maquinaria industrial, aparatos médicos, pesticidas, productos químicos, tecnologías de la información y telecomunicaciones, productos textiles).

Tercer pilar: reglas para abordar los desafíos globales compartidos

- Propiedad intelectual e indicaciones geográficas.

- Aduanas y facilitación de comercio.

- Comercio y desarrollo sostenible (aspectos laborales, sociales, medioambientales).
- Comercio y competencia.

- Empresas públicas y subvenciones.

- Comercio de energía y materias primas.

- Pymes.

- Transparencia.

- Mecanismo de solución de disputas entre Estados.

- Protección de inversiones y solución de conflictos entre inversor y Estado (ISDS, Investor State Dispute Settlement).

El resultado del trabajo del grupo no fue en absoluto sorprendente, ya que, dados los aranceles promedio bajos (en torno al $4 \%$ ), la clave para impulsar un aumento significativo del comercio radicaba en intentar abordar las barreras no arancelarias, barreras que en parte son el resultado de sistemas reguladores diferentes, pero también de otras medidas no arancelarias, como las relacionadas con ciertos aspectos de la seguridad o la protección del consumidor, además de otros obstáculos derivados de las divergencias en las regulaciones.

En el Consejo de Ministros de Comercio del 14 de junio de 2013 se aprobó el mandato del Consejo para iniciar las negociaciones, en forma de una doble decisión (una para materias de exclusiva competencia de la UE y otra para materias de competencia compartida con los Estados miembros), junto con las directrices de negociación.

Por su parte, en EE UU, el 20 de marzo de 2013, el USTR había informado por escrito al Congreso de su intención de negociar, y el nuevo representante, Michael Froman, había anunciado que solicitaría al Congreso la renovación de la «Fast Track» (Trade Promotion Authority) en los siguientes meses.

Finalmente, el 17 de junio de 2013, en los márgenes del G8, los presidentes de EE UU, del Consejo Europeo y de la Comisión $D$ 
Juan Francisco Martínez García y Blanca Revenga Martínez de Pazos

Europea anunciaron en una rueda de prensa conjunta el lanzamiento formal de las negociaciones.

Los objetivos, conforme a la estructura prevista, los vemos a continuación.

\subsection{Acceso a los mercados}

\section{Aranceles}

El objetivo a largo plazo era la eliminación de todos los aranceles, pero a corto plazo se reconocía la sensibilidad de algunos productos, y el desarme arancelario de los mismos sería realizado progresivamente durante periodos transitorios. Se estimaba que no debería existir gran dificultad en alcanzar una eliminación casi completa de aranceles en productos industriales. En productos agrícolas ambas partes parecían tener muy mezclados los intereses ofensivos y defensivos. Aunque los aranceles NMF fuesen bajos, la existencia de crestas arancelarias en algunos sectores económicos de interés justificaría un ejercicio de desarme arancelario que igualaría a Europa con otros países que ya contaban con un acuerdo de libre comercio con EE UU en vigor.

\section{Servicios}

El objetivo era igualar los compromisos con los más amplios ya asumidos con otros países hasta la fecha y solucionar barreras de acceso ya identificadas (salvo en los sectores donde hubiera sensibilidades). En el mercado americano las barreras suelen derivar de la fragmentación legislativa y la regulación subfederal, generándose cargas administrativas que hacen más difícil el posicionamiento en el mercado. En cualquier caso, se hacía necesario identificar las áreas donde sería posible avanzar por la existencia de un interés común. Sectores españoles con intereses ofensivos eran: servicios financieros, servicios de seguridad, energías renovables, eficiencia energética, redes de transporte (autopistas y ferrocarril), energía y telecomunicaciones, protección del medio ambiente, reciclaje y desarrollo de productos biotecnológicos y nanotecnológicos, y administración y gestión de los servicios sanitarios (e-health).

Sobre sectores concretos:

- Aéreo. Había un compromiso de EE UU de iniciar un proceso de liberalización total de la inversión europea (actualmente la legislación de EE UU solo permite el $25 \%$ de propiedad extranjera).

- Financieros. Aunque el comisario europeo para mercado interior, Michel Barnier, se había mostrado favorable a incluir la cooperación regulatoria en materia financiera dentro de las negociaciones del ALC, la reacción estadounidense fue contraria y no parecía posible que se pudiera ir muy lejos en este ámbito dentro del acuerdo.

- Servicios que impliquen flujos de datos transfronterizos. La UE consideraba que el nivel de protección de datos en EE UU era «inadecuado» y por lo tanto no estaba a favor de una propuesta estadounidense de imponer como principio general que «los datos pudiesen intercambiarse libremente entre fronteras".

- Servicios marítimos. Varios países identificaban como un obstáculo a eliminar la Ley de Buques Mercantes americana de 1920, que restringe el transporte de mercancías y pasajeros en aguas estadounidenses a compañías estadounidenses. 
Inversiones

El objetivo era igualar los compromisos con los más amplios ya asumidos por EE UU con otros países hasta la fecha.

EE UU es un país bastante protector, por lo que el interés para Europa, y en particular para España, provenía de conseguir un nivel adecuado de protección a todos los sectores, y no solo a aquellos en los que se hubieran hecho concesiones de acceso a mercado. La protección debía ser horizontal.Y obtener un compromiso por parte de EE UU de implicación en la liberalización en el ámbito subfederal.

\section{Compras públicas}

El objetivo era un acceso mejorado a todos los niveles gubernamentales. En el documento se hablaba de «acceso a oportunidades en todos los niveles», lo que indicaba que también se podrían incluir niveles subfederales. Se entendía que solo bastaría que el acceso supusiera una «mejora sustancial».

\section{2. Área de regulación y barreras no arancelarias}

Cooperación regulatoria y barreras no arancelarias

De un lado, se pedía encontrar un equilibrio entre la necesidad de reducir costes y retrasos administrativos innecesarios derivados de una regulación y, de otro, que se alcanzasen los niveles de protección de la salud, seguridad $o$ del medio ambiente $u$ otros objetivos legítimos.

Como novedad, se hablaba de involucrar más a los reguladores.
La clave de este apartado estaba en que se pretendía crear unos mecanismos para lograr compatibilidad/armonización de las regulaciones futuras, así como la equivalencia/reconocimiento mutuo en las existentes.

- Además de pedir que se incluyeran SPS plus, destacaba que propusiera, entre otras cuestiones, crear un mecanismo continuo o permanente para solucionar los contenciosos SPS, y se mencionaba que las medidas SPS debían basarse en valoraciones científicas aceptadas internacionalmente.

- TBT plus: el enfoque de foro bilateral se sustituía por el de crear un mecanismo continuo. Este capítulo debía buscar reducir requisitos de certificaciones y pruebas.

- Temas horizontales sobre coherencia y transparencia regulatoria: se preveían consultas en los momentos iniciales y revisiones periódicas y seguimiento de buenas prácticas.

- Compromisos sectoriales específicos para lograr cierta armonización/compatibilidad en determinados bienes y servicios.

- Crear un mecanismo para detectar futuros problemas.

Asimismo, el informe hacía una referencia a seguir progresando en la eliminación de barreras SPS que afectan al comercio bilateral.

\subsection{El área de reglas sobre temas globales}

Finalmente, el informe señalaba que tanto la UE como EE UU contribuirían a fortalecer el sistema multilateral desarrollando nuevas reglas sobre temas globales. 
Juan Francisco Martínez García y Blanca Revenga Martínez de Pazos

Derechos de propiedad intelectual

En normas de derechos de propiedad intelectual el objetivo era muy poco ambicioso: ambas partes se comprometían a analizar un número limitado de cuestiones y además sin prejuzgar el posible resultado. No se mencionaban las indicaciones geográficas, y si bien es cierto que el comisario De Gucht daba por hecho que se incluirían, la posición de EE UU no auguraba una negociación fácil.

\section{Medio ambiente y trabajo}

El informe decía que se tendrían en cuenta los avances y el trabajo realizados en otros acuerdos bilaterales, como los negociados por la UE (ALC UE-Singapur, que incluye un anexo sobre tecnologías verdes).

\section{Otros retos y oportunidades globales}

El informe ampliaba el abanico de áreas relacionadas con el comercio donde se puede buscar algo de acercamiento entre ambos bloques (aduanas, política de competencia, empresas públicas, materias primas y energía, pymes y transparencia), lo que se interpretaba como un modo de ayudar a recuperar el liderazgo transatlántico en el debate a nivel multilateral.

\section{Las negociaciones del TTIP}

La primera ronda de negociación del TTIP, inaugurada oficialmente por el USTR, Michael Froman, tuvo lugar entre el 8 y el 12 de julio en Washington. En ella participaron alrededor de 150 negociadores de la UE y EE UU, divididos en 24 grupos de negociación y liderados por el negociador jefe de la UE, Ignacio García
Bercero, y de EE UU, Daniel Mullaney. De los 60-65 negociadores desplazados por la Comisión desde Bruselas, cerca de la mitad eran responsables de cuestiones regulatorias en diversas Direcciones Generales, mientras que la otra mitad procedía de DG Trade.

Los Estados miembros tuvieron la oportunidad de debatir con la Comisión los preparativos de esta primera ronda, así como los documentos (initial position papers y concept papers) preparados por la Comisión para compartir con EE UU durante estas primeras sesiones: paquete de regulación sobre automóviles, químicos, farmacéuticos y equipos médicos, SPS, TBT, cuestiones horizontales sobre cooperación regulatoria, contratación pública, desarrollo sostenible, cuestiones de competencia, empresas públicas y subvenciones, energía y materias primas, servicios financieros, tecnologías de la información y la comunicación (TIC), solución de disputas inversor-Estado (ISDS), así como una propuesta de texto sobre servicios, inversión y comercio electrónico.

Los Estados miembros realizaron sus comentarios sobre los documentos, dando en líneas generales su apoyo a los mismos como base para la primera ronda de negación.

Al término de la semana, se había llevado a cabo una discusión sustancial de todos los elementos que se pretendía incluyese el acuerdo, identificando las áreas de convergencia y explorando algunas posibilidades en las áreas divergentes, y se habían establecido los grupos de trabajo para cada una de ellas. Se había hablado, entre otras cuestiones, de acceso a mercado de productos agrícolas e industriales, servicios transfronterizos, comercio electrónico y telecomunicaciones, servicios financieros, reglas de origen, contratación pública, inversiones, energía y materias primas, coherencia regulatoria y trasparencia, SPS, TBT, anexos sectoriales/ $D$ 
cooperación regulatoria, derechos de propiedad intelectual, desarrollo sostenible, pymes, solución de disputas, competencias, aduanas y facilitación del comercio y empresas estatales, entre otros temas. La ronda permitía constatar un alto grado de ambición de ambas partes.

La Comisión destacó la importancia que concedería en estas negociaciones a la política de comunicación y transparencia hacia los medios, el público y todos los interesados, y hubo varias ruedas de prensa durante la semana de negociaciones, incluida una a su término, el 12 de julio de 2013. Además, el 10 de julio se celebró también una sesión conjunta en Washington de los negociadores del USTR y de la UE con los stakeholders en la que participaron profesionales de la industria, académicos, consumidores, sindicatos, ONG, etcétera, con más de 350 participantes.

DG Trade también celebró una sesión informativa similar con la sociedad civil (Civil Society Dialogue) el 16 de julio en Bruselas, con más de 150 representantes de ONG y asociaciones industriales.

En esa misma línea de transparencia se creó incluso una cuenta oficial de Twitter sobre el TTIP para información general, y la Comisión decidió publicar en su página web varios de los initial position papers que presentó a los americanos durante la primera ronda, en concreto los relativos a cuestiones regulatorias horizontales, TBT, SPS, compras públicas, desarrollo sostenible, energía y materias primas.

En los años 2014, 2015 y 2016 se sucedieron las rondas con una periodicidad casi trimestral y se fue avanzando en el intercambio y la consolidación de textos. También se produjo el intercambio de dos ofertas arancelarias.

Tras tres años y medio de negociaciones y un total de quince rondas, aquellas se interrumpieron en noviembre de 2016.
El estado de situación de las negociaciones en los tres pilares lo vemos a continuación.

\subsection{Primer pilar: acceso a mercado}

Oferta arancelaria. Las ofertas sobre la mesa cubrían el $97 \%$ de las líneas arancelarias y, aunque en las últimas rondas se habían discutido las posibilidades de mejorar las ofertas, no se llegó a iniciar ninguna discusión. En relación con el texto sobre agricultura e indicaciones geográficas (IG), quedaron abiertas las cuestiones relacionadas con la inclusión del Acuerdo del Vino de 2006 y la petición europea de proteger los semigenéricos del acuerdo de 2006. Se barajaban varias formas de protección compatibles con la legislación de EE UU, como posibles landing zones en IG, utilizando todo el espacio posible para dar más protección a las IG a través de estándares de identidad, la normativa sobre etiquetado y otros.

En exportaciones y créditos a la exportación se estaba negociando todavía hasta qué punto se quería ir más allá de lo acordado en Nairobi en diciembre de 2015, en la Conferencia Ministerial de la OMC.

En servicios persistían las diferencias en cuanto a las ofertas, pero se logró avanzar bastante en la consolidación del texto. En lo que se refiere a servicios financieros, se concluyó la revisión de la oferta de la UE y gran parte de la oferta americana. Se había avanzado también en la consolidación del texto en servicios financieros, en particular las disposiciones relativas a definiciones, excepciones y aspectos institucionales.

Contratación pública. Aunque técnicamente la oferta americana era más ambiciosa de lo negociado en GPA, esta todavía no reflejaba el grado de ambición que la UE esperaba para $\triangleright$ 
estas negociaciones. En la última ronda, las discusiones se centraron en el texto sobre contratación pública, principalmente en las disposiciones relativas a transparencia, trato no discriminatorio y consideraciones ambientales, sociales y de derechos del trabajador en los procedimientos de contratación.

Reglas de origen. En la parte horizontal del protocolo de origen quedaba bastante trabajo en lo que se refiere a la verificación y casos de denegación de preferencias. En lo que se refiere a las reglas específicas de producto (reglas de lista), también había diferencias que discutir, sobre todo en reglas para productos agroalimentarios, las últimas que se intercambiaron, pero también en productos industriales y textiles.

\subsection{Segundo pilar: aspectos regulatorios}

Cooperación regulatoria. El trabajo en los últimos meses se centró en la consolidación de las propuestas por ambas partes sobre cooperación regulatoria y buenas prácticas regulatorias. Subsistían dificultades significativas y todavía estaba por ver si era posible encontrar landing zones en este ámbito.

Medidas sanitarias y fitosanitarias (SPS). Persistían numerosas diferencias, entre ellas el reconocimiento de las inspecciones, el trato a la UE como entidad única, equivalencias, auditorias, bienestar animal, la inclusión de la resistencia antimicrobiana en el acuerdo, etcétera.

Obstáculos técnicos al comercio (TBT). En las últimas reuniones se dedicó bastante tiempo a discutir la evaluación de la conformidad. Se indicaron ideas a EE UU sobre cómo progresar para establecer un marco que permita a los organismos americanos emitir certificados de conformidad con los estándares europeos, pero se dejó claro que solo sería posible si, en contrapartida, estaban dispuestos a buscar un modo de reducir los costes de evaluación en el sector de maquinaria.

Sectores. Tras negociaciones intensas en cinco de los nueve sectores específicos, los sectores de automoción y farmacéutico eran los más avanzados. En automoción se trabajaba para conseguir la equivalencia en determinados estándares de protección y en farmacéuticos se estaba discutiendo cómo actualizar el acuerdo sobre reconocimiento mutuo de 1998. Las discusiones eran algo más problemáticas en el área de aparatos médicos, y en productos textiles las posiciones se habían acercado para sentar las bases de una futura cooperación. En cosméticos se habían aproximado las posturas, pero todavía había desacuerdos importantes. Menos avanzadas se encontraban las discusiones en tecnologías de información y comunicaciones, y pesticidas.

\subsection{Tercer pilar: reglas}

Desarrollo sostenible. Ambas partes habían intercambiado propuestas en materia de derechos laborales y disposiciones medioambientales, y si bien a nivel político EE UU había manifestado su intención de ir más allá de lo acordado en TPP, la propuesta americana era menos ambiciosa de lo que la UE esperaba. Los aspectos más complicados para EE UU eran la ratificación de los ocho convenios fundamentales de la Organización Internacional del Trabajo (OIT) y las cuestiones relativas al cambio climático.

Las disposiciones en materia de procedimiento, incluida la solución de disputas, todavía estaban pendientes, aunque había habido discusiones preliminares sobre el tema. 
Facilitación del comercio. En la última ronda se habían logrado avances en distintos puntos, como el procedimiento de admisión temporal de mercancías y el tratamiento de mercancías tras su reparación. Se habían discutido algunos aspectos como el desarrollo de operadores autorizados conjuntos, armonización del requerimiento de datos de ambas partes y la creación de una ventanilla única común, TIC, pagos electrónicos, y otros, pero quedaban sin resolver diversas cuestiones, como, por ejemplo, las tasas.

Propiedad intelectual. Las disposiciones relativas a los acuerdos internacionales y cooperación estaban cerca de consolidarse y las negociaciones estaban avanzadas también en otras áreas, como ejecución aduanera y cooperación.

Energía y materias primas. La UE había presentado en la penúltima ronda algunos ajustes en la fijación de precios y restricciones a la exportación de los monopolios de exportación, y aspectos relativos al tránsito, pero no se había llegado al punto de pensar en una consolidación de los textos.

Competencia. Se consiguió llegar a un entendimiento en prácticamente todas las áreas, pero quedaba trabajo por hacer en transparencia en los procedimientos y el derecho a la defensa. Persistían dificultades en el área de empresas públicas porque los enfoques tenían distinto alcance y la UE quería que las disciplinas tuviesen alcance subfederal.

Pymes. Era el texto más avanzado, aunque subsistían algunas diferencias sobre umbrales, NTB y contratación pública.

Solución de diferencias inversor-Estado. No había progresos en la convergencia de posturas y solo había habido avances en aquellas partes del texto en las que las partes tienen enfoque y propuestas de texto similares, como son resolución amistosa de disputas, mediación, consolidación de quejas múltiples, quejas infundadas, etcétera.

Anticorrupción. Era una prioridad para EE UU y se contemplaba estudiar la inclusión de un posible texto que no llegó a debatirse.

Disposiciones institucionales y legales. Las negociaciones sobre las disposiciones legales e institucionales se habían centrado en la parte referente a las definiciones y aspectos institucionales y subsistían diferencias en las cuestiones institucionales y algunos otros aspectos más formales, como aceptar los textos auténticos en las veintitrés lenguas comunitarias.

La última ronda de negociación, la decimoquinta desde que comenzaran las negociaciones en 2013, tuvo lugar del 3 al 7 de octubre de 2016 en Nueva York, y una vez constatado que el cierre político del acuerdo no era posible, tras un intento por parte de EE UU de acelerar el cierre con un acuerdo político basado en el estudio de posibles landing zones, en esos contactos bilaterales en noviembre se exploraron posibles vías para poder aprovechar el trabajo hasta la fecha.

Hubo un comunicado conjunto UE-US (Joint Statement o Joint Report), el 17 de enero de 2017, que expresaba ese deseo, y se constató que lo único que parecía viable sería seguir avanzando con el Acuerdo de Reconocimiento Mutuo (ARM) en el sector farmacéutico, dado que ya existía un acuerdo previo de 1998.

Las negociaciones sobre reconocimiento de las inspecciones sobre buenas prácticas en la fabricación en la industria farmacéutica continuaron en enero en el marco del acuerdo de 1998 y se llegó a otro que se está implementando.

Para explicar los motivos por los que no se consiguió llegar a un acuerdo se pueden identificar algunos problemas concretos en áreas importantes. Pilar a pilar. 
Acceso a mercado. Compras públicas (Buy America), diferencias en servicios y transporte marítimo, etcétera.

Regulación. Se había avanzado mucho en el conocimiento mutuo y en particular en productos farmacéuticos, aparatos médicos y seguridad en los vehículos, pero en la parte general subsistía una diferencia de enfoque, y hubieran hecho falta más reuniones para seguir avanzando en el resto de los sectores elegidos. Viendo el lado positivo, la situación actual debería permitir mantener una dinámica de contactos y colaboración.

Reglas. Hubo progresos allí donde no había una plantilla previa y fue más difícil avanzar en las áreas donde ambas partes ya contaban con una plantilla o una posición muy consolidada, como, por ejemplo, el mecanismo para la resolución de diferencias entre los inversores y los Estados. También quedaban incógnitas a despejar en los subsidios a las empresas públicas y en lo relativo al comercio y desarrollo sostenible. En lo referente a subvenciones a empresas públicas había una posición próxima y en materia de derechos laborales parece que habría podido haber margen para trabajar con terceros países.

Vista la imposibilidad de seguir con las negociaciones, la Comisión se propuso como objetivo intentar mantener una agenda de comercio positiva con EE UU, y con ese espíritu se emitió un comunicado conjunto de 17 de enero.

\section{Las relaciones comerciales transatlánticas tras el TTIP}

La nueva Administración cambió notablemente el enfoque de la política comercial y eso afectó a las relaciones comerciales transatlánticas, al igual que al resto de las relaciones comerciales con otros socios.

La nueva posición parece que descansa en el supuesto de que, en las negociaciones comerciales, a causa de la multilateralización de las negociaciones, EE UU ha estado desaprovechando su posición de dominio y liderazgo en el mundo y que su déficit comercial se justifica por el comportamiento desleal de las empresas o de los países con los que EE UU registra un déficit comercial.

De hecho, una orden ejecutiva que solicitaba al Departamento de Comercio la elaboración de un informe (que no fue hecho público) sobre déficits comerciales significativos fue emitida el 31 marzo de 2017, junto a otras cuatro órdenes ejecutivas emitidas para:

- Reforzar la preparación y ejecución de nuevos expedientes antidumping y antisubvención y la identificación de violaciones de la ley de aduanas.

- Reforzar el Buy and Hire American.

- Abordar violaciones y abusos de los acuerdos comerciales.

- Establecer la oficina para la política comercial y de manufactura.

Los primeros seis meses de 2017 dan una buena idea de la nueva orientación de la nueva política comercial, respondiendo a ese objetivo de reducir el déficit comercial en el propio ámbito del comercio.

El resultado inmediato ha sido:

- Un natural y considerable aumento de las fricciones comerciales, que ha generado múltiples crónicas en los medios de comunicación sobre un clima de guerra comercial y que también se ha dejado sentir en las relaciones transatlánticas. 
- Una bilateralización de las negociaciones, previa retirada de las negociaciones plurilaterales.

- Renegociación de acuerdos anteriores.

En este contexto se entiende la retirada de EE UU del acuerdo Transpacífico y las denuncias y posteriores renegociaciones del NAFTA y el Acuerdo con Corea, por ejemplo. Los siguientes en la lista en este proceso parece que serán Japón y la UE.

Otra consecuencia del más agresivo nuevo enfoque en las relaciones exteriores y comerciales, en general, ha sido una revisión y endurecimiento de la política comercial unilateral, con la apertura de nuevos casos de defensa comercial (medidas antidumping o derechos compensatorios) ${ }^{1}$ y también la revisión o interpretación de decisiones anteriores como la reciente revisión de la clasificación arancelaria de algunos quesos elaborados con leche de oveja.

Ante esta nueva situación, la Comisión Europea y sus Estados miembros se han debatido desde principios de 2017 entre la necesidad de mostrar una posición igualmente dura en los conflictos que han ido surgiendo y el deseo de mantener una agenda positiva que evitase una confrontación abierta.

De ese modo, por un lado, en contactos bilaterales con la Administración americana, se avanzó hacia el cierre del acuerdo de reconocimiento mutuo de las inspecciones en las industrias farmacéuticas, se ha buscado solucionar de forma amigable el conflicto por la prohibición de importación de la carne hormonada en Europa (la gestión del contingente de carne de

1 Entre enero y julio de 2017 EE UU inició 47 investigaciones contra 11 productos, frente a 33 y 10 productos en el mismo periodo del año anterior, ampliando la cobertura geográfica y volviendo a utilizar medidas de salvaguardia — dos- para paneles fotovoltaicos y lavadoras. vacuno acordado como compensación tras la pérdida del panel en la OMC sobre la prohibición de comercializar en la UE carne de animales tratados con hormonas, tras la aprobación de la Directiva denominada «Hormonas» de 1988) y se ha promocionado activamente la colaboración junto con Japón en una iniciativa de reforma de la OMC, pero, por otro lado, se ha cuestionado en esta organización la imposición de aranceles a los productos de acero y aluminio $^{2}$ (y se ha respondido con medidas de reequilibrio) y también se han cuestionado en Ginebra otras iniciativas como los derechos antidumping y antisubvención aplicados a las aceitunas de mesa españolas.

Otros temas que han desfilado por las diferentes reuniones y contactos bilaterales en los dos últimos años han sido: la reforma fiscal en EE UU, varios procedimientos antidumping, antisubvención o salvaguardias (alambrón de acero al carbono, tuberías mecánicas, paneles fotovoltaicos, lavadoras, acído cítrico, y el caso de las ya mencionadas aceitunas de mesa, caso este último de especial relevancia para España, que es el único país investigado); y otros temas destacados por parte de EE UU: el flujo de datos asociado a las operaciones comerciales, la interpretación del artículo 15 del protocolo de Adhesión de China a la OMC y los certificados suplementarios en las patentes farmacéuticas.

Los casos Airbus y Boeing y las diversas iniciativas y temas asociados a la reforma de la OMC, incluyendo el tema estrella del funcionamiento del Órgano de Apelación del mecanismo de solución de diferencias, merecen $\triangleright$

2 El 8 de marzo de 2018 el presidente Trump adoptó medidas por motivos de seguridad nacional bajo la sección 232 de la Trade Expansion Act de 1962, que implicaban la imposición de una tasa adicional del 10\% a todas las importaciones de aluminio y de otra del $25 \%$ para el acero. Tras dos suspensiones temporales, estas medidas se aplicaron a la UE desde el 1 de junio. 
mención aparte porque en la OMC se mezclan los temas de cooperación en una agenda positiva como el impulso a una reforma del acuerdo antisubvención que contemple las subvenciones industriales con criterios más estrictos, con otros con una posición de clara discrepancia como el Órgano de Apelación.

Un hito especialmente significativo en el accidentado camino que han seguido las relaciones transatlánticas en el ámbito de comercio desde 2017 podría considerarse el comunicado conjunto de los presidentes Trump y Juncker tras su reunión el 25 de julio de 2018, que la Comisión interpreta como un posible inicio del proceso para desarrollar un marco potencialmente algo más estable para las relaciones comerciales transatlánticas que la montaña rusa del año y medio transcurrido hasta entonces.

En dicha reunión, Juncker y Trump llegaron a un acuerdo político para:

- Trabajar juntos para lograr un comercio bilateral de productos industriales (excluidos los automóviles) libre de aranceles, de barreras no arancelarias y de subsidios; para reducir las barreras y aumentar el comercio de servicios, productos químicos, farmacéuticos, productos médicos y soja.

- Favorecer la exportación de gas natural licuado desde EE UU en el marco de una cooperación estratégica reforzada en el ámbito de la energía.

- Entablar un diálogo sobre normas para facilitar el comercio y reducir los obstáculos burocráticos y, en consecuencia, los costes.

- Trabajar conjuntamente con otros socios afines para reformar la OMC y abordar las prácticas comerciales desleales, incluida la vulneración de derechos de propiedad intelectual, la transferencia forzada de tecnología, las subvenciones industriales, las distorsiones creadas por las empresas públicas y el exceso de capacidad.

Para avanzar en la preparación de las negociaciones y llevar adelante esta agenda conjunta, el comunicado preveía crear un grupo de trabajo ejecutivo conjunto.

El comunicado también establece que durante los trabajos de este grupo no se tomarán medidas contrarias al espíritu de este acuerdo, salvo que alguna de las partes decida interrumpir los contactos, en referencia implícita a la potencial implantación de aranceles a la importación de automóviles y componentes al amparo de una nueva investigación acometida por el Departamento de Comercio, cuyo informe estaba siendo elaborado en ese momento y que ha sido finalmente remitido a la Casa Blanca el 17 de febrero de 2019.

Por último, en el comunicado también se recogía la voluntad de resolver el conflicto creado por la imposición de EE UU de aranceles sobre el acero y el aluminio.

El grupo de trabajo se creó inmediatamente y ha centrado su labor en la identificación de áreas de trabajo en las que se pudiera avanzar fácilmente, sobre las áreas en las que ya existe un marco jurídico claro y en las que se han identificado beneficios mutuos, evitando áreas de potencial desacuerdo o conflicto.

La Comisión ha publicado un informe sobre el trabajo del Grupo de Trabajo Ejecutivo conjunto UE-EE UU, donde destacan las acciones detectadas en el corto y medio plazo para facilitar el comercio transatlántico en áreas como el reconocimiento de la inspección de buenas prácticas en productos farmacéuticos (extendiendo al alcance del actual acuerdo), $\triangleright$ 
aparatos médicos, evaluación de conformidad y ciberseguridad:

- Se ha llegado a un acuerdo, en principio para ampliar el alcance del Acuerdo de Reconocimiento Mutuo, para incluir medicamentos veterinarios. Las dos partes trabajarán para iniciar en 2019 inspecciones conjuntas de las instalaciones de fabricación de vacunas humanas y productos farmacéuticos derivados del plasma, para explorar el camino para otra posible extensión futura a estas áreas, a más tardar en 2022. Una vez que el acuerdo se haya implementado por completo, se podrían evitar cientos de inspecciones de instalaciones farmacéuticas.

- La UE facilitará el uso de informes de auditoría únicos para los aparatos médicos (una iniciativa del Foro Internacional de Reguladores de Aparatos Médicos, IMDRF). La UE y EE UU cooperarán para garantizar la alineación de las especificaciones de la base de datos electrónica para los identificadores de dispositivos únicos (UDI) y desarrollarán un plan para la prueba bilateral de compatibilidad de las respectivas bases de datos UDI, en concierto con los esfuerzos actuales de IMDRF.

- La UE (DG CNECT) y EE UU (NIST) han acordado intensificar su cooperación en el área de la ciberseguridad. Se espera que se lleve a cabo una primera reunión durante la primera mitad de 2019.

- La UE también ha indicado que está dispuesta a negociar un acuerdo internacional para reducir los costes de la evaluación de la conformidad en el comercio transatlántico, siempre que se cumplan las condiciones adecuadas para garantizar la confianza en la evaluación de la conformidad en ambos lados del Atlántico. La reducción de los costes de evaluación de la conformidad para los operadores económicos en ambos lados del Atlántico, sin bajar las normas de seguridad o las garantías de calidad necesarias para los consumidores, facilitaría el comercio, beneficiando especialmente a las pequeñas y medianas empresas, que son las más perjudicadas por los costes que implica la obtención de la certificación de sus productos para exportar a mercados en los que se aplican diferentes requisitos y procedimientos reglamentarios.

Como resultado de los contactos en el Grupo de Trabajo Ejecutivo conjunto UE-EE UU, ambas partes han puesto en marcha los mecanismos legales para poder iniciar un nuevo proceso de negociaciones comerciales.

El 11 de enero de 2019, el USTR publicó los Objetivos Específicos de Negociación (Summary of Specific Negotiating Objectives) para un acuerdo comercial con la UE, que ha remitido al Congreso de EE UU. Los objetivos son muy amplios, yendo mucho más allá de lo recogido en la declaración conjunta Juncker-Trump de julio, pero menciona la posibilidad de negociar en varias fases. Destacan la inclusión de la agricultura, cuestiones sanitarias y fitosanitarias, derechos de propiedad intelectual — sin referencia a IG- y contratación pública, áreas todas ellas en las que hay divergencias muy notables.

Por su parte, el 18 de enero de 2019 la Comisión publicó dos propuestas de mandato, autorizando la apertura de negociaciones con EE UU para la eliminación de aranceles en $\triangleright$ 
bienes industriales y para la negociación en materia de evaluación de conformidad, que ha remitido al Consejo.

La continuación del proceso podría ser el inicio de negociaciones para cerrar en un plazo relativamente corto (quizá menos de un año) un desarme arancelario en productos industriales y la negociación en paralelo de uno o varios acuerdos más en el ámbito de la regulación sectorial.

En paralelo también se ha estado trabajando en el seno de la iniciativa trilateral apadrinada por Japón y lanzada en la Duodécima Conferencia Ministerial de la OMC en diciembre de 2017 en Buenos Aires, que mantuvo su quinta reunión ministerial para tratar posibles reformas de la OMC en enero, y en la que se ha acordado cerrar el documento conjunto sobre subvenciones industriales durante la primavera.

\section{Conclusión}

Como se preveía, el cambio en la política comercial en EE UU, a principios de 2016, ha generado no pocas incertidumbres, también en las relaciones transatlánticas, por el objetivo, ya que se dice orientado a un único o fundamental fin, que sería la reducción del déficit comercial, $y$, sobre todo, por los instrumentos utilizados para lograr ese fin, los tradicionales de la política comercial en todas sus vertientes: multilateral (OMC), bilateral y unilateral, pero con un predominio de las herramientas unilaterales y un uso defensivo más agresivo. Esa combinación de objetivo e instrumentos resulta hasta cierto punto sorprendente y encuentra poca justificación en el análisis económico, que correlaciona mucho más la existencia de los déficits comerciales con la manipulación del tipo de cambio y el desequilibrio en las finanzas públicas. Quizá haya que leerla en clave política.

En relación con las negociaciones comerciales bilaterales en un sentido amplio, parece claro que de momento no se reanudarán, y el TTIP pasaría a ser historia. Los contactos bilaterales se han mantenido y podría empezarse a negociar un acuerdo de alcance limitado en los próximos meses, pero se vive en un estado de sobresalto permanente y es igualmente posible que las negociaciones se interrumpan si se introducen nuevas medidas unilaterales, porque el diálogo en las relaciones bilaterales desde 2016 es un tira y afloja constante que hace imposible predecir hacia dónde se acabarán dirigiendo las conversaciones. 